\title{
Factors Influencing Prescribing Practices of Medical Practitioners in Public and Private Health Facilities in Dar es Salaam, Tanzania
}

\author{
Appolinary AR Kamuhabwa ${ }^{1 \star}$ and Sunday Kisoma ${ }^{2}$ \\ ${ }^{1}$ Unit of Pharmacology and Therapeutics, School of Pharmacy, Muhimbili University of Health and Allied Sciences, ${ }^{2}$ Tanzania \\ Food and Drugs Authority, Dar es Salaam, Tanzania
}

*For correspondence: Email: enali2012@gmail.com, akamuhabwa@muhas.ac.tz, Tel: +255 757 576985; Fax: +255 222150465

Received: 5 August 2014

Revised accepted: 8 October 2015

\begin{abstract}
Purpose: To determine the factors that influence prescribing practices of medical practitioners in public and private health facilities in Dar es Salaam, Tanzania

Methods: One hundred and ninety two (192) medical practitioners from 11 public and 3 private health facilities of Dar es Salaam, Tanzania were interviewed for the criteria they consider when making prescribing decisions. Systematic sampling was used to obtain the required number of medical practitioners working in the hospitals, while for those working in the health centers convenience sampling was used.

Results: Medical information from textbooks (64\%) and internet (63\%) were the main sources of prescribing information among medical practitioners. In comparison, medical practitioners in private health facilities (97\%) were more concerned with proven effectiveness of drugs than those working in public health facilities $(74.2 \%, p=0.001)$. Cost of drug to patients was considered much more by practitioners in public health facilities (48.4\%) than their counterparts in private health facilities $(24.3 \%$, $p=0.010)$. Availability of drugs in the health facility influenced prescribing decisions by a majority of prescribers from public health facilities (53.5 \%) than those working in private health facilities (18.9\%, $p$ $=0.000$ ).

Conclusion: There are substantial differences between prescribers working in public and private health facilities with regard to the factors which influence their prescribing decisions. In order to promote rational use of medicines, these factors should be considered by health planners when formulating policies and allocating resources in health facilities.
\end{abstract}

Keywords: Prescribing practice, Medical practitioners, Health facilities, Prescribing information, Drug costs, Rational use, Drug effectiveness

Tropical Journal of Pharmaceutical Research is indexed by Science Citation Index (SciSearch), Scopus, International Pharmaceutical Abstract, Chemical Abstracts, Embase, Index Copernicus, EBSCO, African Index Medicus, JournalSeek, Journal Citation Reports/Science Edition, Directory of Open Access Journals (DOAJ), African Journal Online, Bioline International, Open-J-Gate and Pharmacy Abstracts

\section{INTRODUCTION}

Surveys conducted in many of the developing countries have shown a significant degree of inappropriate use of drugs in their health care facilities [1]. In most of these studies the average number of drugs per encounter and prescriptions of one or more antibiotics were high [2]. Unnecessary prescription of injectable was also very high. Several factors have been identified to influence practitioners' prescribing decisions and practices [3]. Some factors such as the physicians' age, gender, socio-economic characteristics of the practicing environment, and 
the healthcare demand are fixed and may not offer much opportunity for modification and improvements in prescribing behavior [4]. However, other factors including physicians' level of education and experience, frequency of visits by pharmaceutical sales representatives, number of patients examined per day, and various social factors are amenable to change and can be modified to improve physicians' prescribing behavior $[5,6]$.

In developing countries many factors have been identified as the main contributors of the problem of irrational use of drugs. Such factors include lack of regular and reliable facilities which provides up to date and unbiased information on the currently used drugs, influence of pharmaceutical sales representatives and inadequate training and professional development $[2,7]$. Other factors include poor communication between health professional and patients regarding the basic information about the use of drugs.

Most of the studies done in Tanzania on this area have examined the prescribing behavior of medical practitioners working in church-owned and public health facilities by using WHO drug use indicators [8,9]. Prescribing patterns discovered from these studies must have the underlying reasons as to why the medical practitioners prescribe irrationally and in the way that they do. Therefore, the objective of this study was to determine the factors which influence prescribing practice in public and private health facilities in Dar es Salaam, Tanzania. Identification of these factors is important in order to institute the necessary measures for policy and regulatory interventions to enhance rational use of medicines.

\section{EXPERIMENTAL}

\section{Study design and sampling}

The study was conducted from March to June 2013 in Dar es Salaam, Tanzania. Dar es Salaam was selected as the study site because it is the largest City in Tanzania with many health facilities both in urban and peri-urban areas, including the biggest referral hospital and four of the biggest private hospitals in the country. In this study, 13 health facilities including 6 health centers, 4 public hospitals and 3 private hospitals were used. The medical practitioners enrolled in the study included Medical Specialists, Resident Medical Officers, Medical Officers, Intern
Doctors, Assistant Medical Officers and Clinical Officers.

A descriptive cross sectional study was used to assess the factors that influence prescribing practices of medical practitioners in Dar es Salaam. The study used a stratified sampling method in order to obtain a good representation of the required health facilities as well as all the important cadres of medical practitioners. This was done by assigning health facilities into referral hospitals, municipal hospitals, private hospitals and health centers. The three largest private hospitals were conveniently selected. These are Aga Khan Hospital, Mission Mikocheni Hospital and TMJ Hospital. Public health facilities were grouped into three strata according to their levels, i.e., National Hospital, Municipal hospitals and Health Centers. In this case, the Muhimbili National Hospital, Municipal Hospitals and six health centers were conveniently included in the study. Systematic sampling was used to obtain the required number of medical practitioners from each health facility to be enrolled for the study. Because of the small number of medical practitioners in the health centers, all those who were available during the time of the study were enrolled into the study.

\section{Data collection}

Data were collected from March to June 2013. Interviews were conducted using selfadministered questionnaires at the health facilities. The questionnaire contained 26 questions including medical practitioners' demographic characteristics, prescribing practices, sources of prescribing information and their extent of use, practitioner's attitudes towards use of generic medicines, and practitioners' attitudes towards new discoveries in medicine, and medicines safety. Based on the specific category to be assessed, assessment of prescribers' attitude was done using Likert scale in which 5 was the lowest indicator for positive attitude, while 17 indicated the most negative attitude [10].

\section{Data analysis}

Data were analyzed using Statistical Package for Social Sciences (version 15.0) computer software. Questions on attitudes were transformed and scales assigned before frequencies were run in order to determine proportions of medical practitioners on the attitude scales. Comparison of practitioner's responses from private health facilities with those from public health facilities was done by cross tabulation against different attributes which 
frequencies had been run earlier and as per the specific objectives of the study. The comparisons between the two groups were done by performing a Chi-square test at $95 \%$ confidence intervals. $P<0.05$ was taken as statistically significant.

\section{Ethical considerations}

The ethical approval to conduct the study was sought from the Research and Publications Committee of the Muhimbili University of Health and Allied Sciences. The permission to conduct the study in the health facilities was sought from the respective health facilities' management. Study participants were informed on the purposes of the study, and written consent was then obtained from the study participants.

\section{RESULTS}

A total of 192 medical practitioners were enrolled into the study. The type of health facilities and the respective number of medical practitioners who were interviewed in this study are shown in Table 1.

The socio-demographic characteristics of the study participants are shown in Table 2.

\section{Factors considered by medical practitioners before making prescribing decisions}

Medical practitioners in the private health facilities $(97 \%)$ were more concerned with proven effectiveness of a drug when making their prescribing decisions compared to those working in the public health facilities $(74.2 \%)(p=0.001)$.

Table 1: Medical practitioners and type of health facility $(n=192)$

\begin{tabular}{lllc}
\hline S/N & Health facility & Type of facility & $\begin{array}{c}\text { Number of } \\
\text { practitioners }\end{array}$ \\
\hline 1 & Muhimbili National Hospital & Referral hospital & 50 \\
2 & Mwananyamala Hospital & Municipal hospital & 25 \\
3 & Temeke Hospital & Municipal hospital & 25 \\
4 & Amana Hospital & Municipal hospital & 25 \\
5 & Aga Khan Hospital & Private hospital & 15 \\
6 & Mission Mikocheni Hospital & Private hospital & 15 \\
7 & TMJ Hospital & Private hospital & 10 \\
8 & Magomeni Health Center & Health center & 5 \\
9 & Sinza Health Center & Health center & 5 \\
10 & Mnazimmoja Health Center & Health center & 4 \\
11 & Buguruni Health Center & Health center & 3 \\
12 & Kigamboni Health Center & Health center & 5 \\
13 & Vijibweni Health Center & Health center & 5 \\
\hline
\end{tabular}

Table 2: Socio-demographic characteristics of medical practitioners interviewed in the study $(n=192)$

\begin{tabular}{lcc}
\hline Variable & Number & $\%$ \\
\hline Sex & 124 & 64.6 \\
Male & 68 & 35.4 \\
Female & & \\
& & \\
Age Group (Years) & 70 & 38.5 \\
$21-30$ & 76 & 41.5 \\
$31-40$ & 27 & 15.1 \\
$41-50$ & 9 & 4.9 \\
$>50$ & & \\
& & \\
Cadres & 29 & 15.4 \\
Medical specialist & 67 & 35.6 \\
Medical Officer & 31 & 16.5 \\
Intern Doctor & 20 & 10.6 \\
Assistant Medical Officer & 24 & 12.8 \\
Clinical Officer & 17 & 9.0 \\
Resident & & \\
& & \\
Health Facility & 155 & 80.7 \\
Public & 37 & 19.3 \\
Private & & \\
\hline
\end{tabular}

On the other hand, the cost of the drug to the patient was found to be more influential to practitioners working in the public health facilities (48.4\%) compared to their counterparts working in the private health facilities $(24.3 \%)(p=$ $0.010)$. Availability of drugs in the health facilities was also a factor considered mostly by prescribers from public health facilities (53.5 \%) than those working in the private health facilities $(18.9 \%, p=0.000)$ (Table 3).

\section{Medical practitioners' sources of prescribing information and their preferences}

Results show that $91 \%$ of medical practitioners routinely search for information to guide their prescribing decisions. Information from medical textbooks are widely used (64\%) followed by internet (63\%) and medical journals (39.7\%). Advice from colleagues was reported by $33 \%$ of the respondents while information from pharmaceutical sales representatives ranked the 
Table 3: Comparison of factors considered when making prescribing decisions between practitioners from public and private health facilities $(n=192)$

\begin{tabular}{lccc}
\hline Factor & Private facilities (\%) & Public facilities (\%) & $\boldsymbol{P}$-value \\
\hline Proven clinical effectiveness & 97 & 74.2 & 0.001 \\
Pharmaceutical delivery mode & 13.5 & 17.4 & 0.485 \\
Recommended daily dose & 18.9 & 21.3 & 0.826 \\
Cost to the patient & 24.3 & 48.4 & 0.010 \\
Patient preference & 5.4 & 7.1 & 1.00 \\
Drug availability & 18.9 & 53.5 & 0.000 \\
Others & 0 & 2 & 1.000 \\
\hline
\end{tabular}

Table 4: Comparison of reasons for information search between practitioners from private and public health facilities $(n=192)$

\begin{tabular}{lccc}
\hline Factor & Private facilities (\%) & Public facilities (\%) & $\boldsymbol{P}$-value \\
\hline Dose & 68.6 & 62.0 & 0.559 \\
Adverse drug reactions & 54.3 & 67.6 & 0.167 \\
Interactions & 57.1 & 64.1 & 0.444 \\
Precautions in pregnancy & 54.3 & 58.5 & 0.705 \\
Precautions in breastfeeding & 45.7 & 48.6 & 0.851 \\
Drug toxicities & 20.0 & 41.5 & 0.020 \\
Chronic diseases & 17.1 & 25.4 & 0.379 \\
\hline
\end{tabular}

last $(16.4 \%)$ among the reliable sources of information for prescribing.

Adverse drug reactions (ADRs) (65\%), Dose (63.3\%) and drug-drug interactions (62.7\%) were the most common reasons that make medical practitioners search for information from the above mentioned sources. Other reasons were precaution during pregnancy (57.6\%), breastfeeding (48\%), known toxicity of the drug to vital organs $(37.3 \%)$ and existence of chronic diseases in patients $(23.7 \%)$. With regard to new medicinal products, scientific medical journals were reported to be widely used (45\%) by medical practitioners, followed by internet (44\%) and medical presentations in different forums (38 $\%$ ). Information by pharmaceutical sales representatives were the least $(22.5 \%)$ preferred source of prescribing information when practitioners encountered a new medicinal product.

In order to obtain information about ADRs, prescribers in the private health facilities preferred using publications from medical journals $(42.9 \%)$ compared to those from public facilities $(36.6 \%, p=0.561)$. The extent for the use of medical textbooks was similar among the practitioners working in the public health facilities $(65.7 \%)$ and those working in the private health facilities (64.1\%). Likewise, there were no statistically significant differences observed in the utilization of the rest of the sources of prescribing information between the two groups of medical practitioners $(p>0.05)$.
About a third of the prescribers from private and public health facilities indicated that the main reason for using the above mentioned sources of prescribing information is to get the accurate doses of the drugs. Practitioners from public health facilities were more concerned about occurrence of ADRs (67.6\%), drug-drug interactions $(64.1 \%)$, precautions in pregnancy (58.5\%), breastfeeding (48.6\%), toxicities in vital organs $(41.5 \%)$ and existence of chronic diseases $(25.4 \%)$. With regard to checking for information on drug toxicities on vital organs, 41 $\%$ of practitioners from public health facilities sought information on this aspect compared to $20 \%$ of their counterparts in the private health facilities (Table 4).

\section{Medical practitioners' attitude towards use of generic drugs}

Overall, about $90 \%$ of all medical practitioners were in favor of prescribing generic drugs. More practitioners from public health facilities (45.8\%) prescribed generic drugs compared to those working in the private health facilities (37.8\%). With regard to quality, safety and effectiveness of generic medicines, $50 \%$ of all medical practitioners indicated that the drugs have satisfactory quality, safety and efficacy.

Analysis of data by combination of questions regarding prescribers' attitudes on generic drugs with respect to safety and effectiveness indicated that more than $80 \%$ of medical practitioners had 
positive attitudes towards generic drugs (Table 5).

Table 5: Medical practitioner's attitudes on generic drugs with regard to quality, safety and efficacy $(\mathrm{n}=$ 192)

\begin{tabular}{lcc}
\hline $\begin{array}{l}\text { Attitude } \\
\text { scale }\end{array}$ & $\begin{array}{c}\text { Medical practitioners } \\
\text { grouped according to } \\
\text { attitude scale (\%) }\end{array}$ & $\begin{array}{c}\text { Cumulative } \\
\text { (\%) }\end{array}$ \\
\hline 5 & 10.6 & 10.6 \\
6 & 5.8 & 16.4 \\
7 & 8.5 & 24.9 \\
8 & 12.2 & 37.0 \\
9 & 15.3 & 52.4 \\
10 & 19.0 & 71.4 \\
11 & 13.2 & 84.7 \\
12 & 5.8 & 90.5 \\
13 & 5.8 & 96.3 \\
14 & 1.6 & 97.9 \\
15 & 1.1 & 98.9 \\
16 & 0.5 & 99.5 \\
17 & 0.5 & 100 \\
\hline
\end{tabular}

Comparison between medical practitioners in the public and those in private health facilities shows that majority of practitioners in the public health facilities $(89 \%)$ and those in the private health facilities $(78.6 \%)$ believe that generic drugs are of excellent and good quality. Medical practitioners' opinions on the effectiveness of generic drugs show that $89.2 \%$ of practitioners in the private health facilities believe that generic drugs are of excellent or satisfactory effectiveness compared to $78.7 \%$ of practitioners from public health facilities $(p=$ $0.171)$.

Thirty nine percent (39 \%) of medical practitioners did not believe that high price of new drugs imply better effectiveness compared to those who do believe so (38\%). The similarity in this aspect is regardless of the fact that majority of medical practitioners were in favor of the effectiveness of new drugs (52\%) compared to those (19\%) who believed that there is no significant difference between new drugs and old drugs already available on the market. Combined data on attitudes towards new drug products indicated a balance between the proportion of medical practitioners with positive attitude and those with negative attitude towards generic drugs.

\section{DISCUSSION}

Proven clinical effectiveness was seen as the most important criterion considered by medical practitioners from both private and public health facilities when prescribing. This is likely due to the fact that in Tanzania, like in many other developing countries, treatment especially of most common diseases is often empirical i.e., treatments are started before obtaining laboratory investigation results [11]. In such a situation, most of medical practitioners would prefer to prescribe a drug whose clinical effectiveness is well proven and documented for the suspected indication. This is also in line with the findings of a study that was designed to describe and compare opinions of physicians, clinical pharmacists, and drug formulary committee members with respect to key factors that influence medication prescribing in community hospitals [3]. In the later study, safety, effectiveness and restrictions on prescribing were the most influential factors for prescribing.

The observation that proven clinical effectiveness of the drug was mostly considered by practitioners from private health facilities is due to the fact that in Tanzania, public health facilities are often faced with shortage of medicines [12]. As a result, there is not much to choose from treatment options. Majority of patients visiting these facilities are of lower socio-economic status and therefore may not afford the expensive medications which are most effective for particular disease indications. Subsequently, medical practitioners are confined into prescribing the least expensive available drug that would be affordable to patients [13].

Majority of medical practitioners in this study rely on multiple sources of drug information for prescribing. Similar pattern for use of drug information resources has been reported among medical practitioners in Ireland [14]. In the latter study, drugs and therapeutics bulletin and medical journal articles were rated among the most preferred sources of prescribing information for both old and new medicines. This is somehow different with the findings of the present study where medical textbooks were the most used sources of prescribing information. This is probably due to the fact that medical textbooks are the most accessible sources of prescribing information to medical practitioners in Tanzania [15].

In this study, internet was reported to be widely used by medical practitioners working in the public and private health facilities. It is understandable that there has been a massive move towards an effective use of information and communication technology in all sectors including health care. This has been advantageous in health since medical practitioners can obtain much information on medicine and medical supplies quite easily through the internet. Therefore, it is necessary to 
consider increasing access to computers and internet connectivity in the health facilities.

In this study medical journals were another important source of prescribing information. This could be attributed to the fact that most of the journals contain well researched scientific articles. Therefore information from these sources is most likely to be widely relied upon by medical practitioners for their prescribing. The main challenge regarding the use of this source of information is low capacity of subscription to these journals among medical practitioners in Tanzania.

The use of generic drugs is encouraged because they are cheaper than branded substitutes, and in most cases they have equal potency to that of the branded ones [16]. In a study conducted in twelve developing countries in 1987, only $17 \%$ of drugs prescribed in the rural health facilities were prescribed in their generic names [1]. However, a study conducted in 1993 in Tanzania found that $84 \%$ of drugs were prescribed in their generic forms [17]. Thus the observation that majority $(90 \%)$ of medical practitioners in this study prescribe generic drugs on regular basis is a reflection of the situation in Tanzania where more than $80 \%$ of drugs circulating in the market are generics [18]. This is also in support of the government initiative advocating for the use of generic drugs in order to minimize unnecessary costs of healthcare budgets.

Generally practitioners in the private health facilities have a greater trust in quality, safety and effectiveness of generic drugs. Between the two sets of medical practitioners, those from private health facilities were more in favor of the safety of generic drugs compared to their counterparts from the public health facilities. With regard to medical practitioners' attitudes on new drugs available in the market, the proportion of practitioners who believe that new medicines have greater effectiveness compared to old medicines available in the market was similar to those who were in favor of old medicines. These observations could be due to the fact that majority of drugs circulating in the market in Tanzania are generics [18]. In addition, an innovator drug will be registered long after a generic drug has been registered, and therefore, medical practitioners will have already experienced the effectiveness and other benefits of the existing generic drug.

\section{CONCLUSION}

This study has identified that prescribers use a variety of sources of information to support their prescribing decisions. In terms of the factors considered by prescribers to prescribe a particular drug, there were differences between those working in the public health facilities and private facilities. However, for majority of prescribers, cost of drugs to the patients was an important factor influencing prescribing. In order to increase access to essential medicines, the government should expand coverage of the health insurance scheme beyond the government employees.

\section{Limitation of the study}

The study was conducted in Dar es Salaam, which is a commercial capital with relatively well staffed health facilities. Therefore, the situation may be different in other health facilities, especially in the rural areas of the country. It is therefore recommended that a similar study be conducted in other regions in the country to determine the factors that influence prescribing practices of medical practitioners in these areas.

\section{ACKNOWLEDGEMENT}

The authors wish to express their sincere appreciation to the medical officers in charge of the three municipal hospitals and Muhimbili National Hospital for granting permission to conduct the study in the health facilities. Thanks also to the management of the private hospitals for granting permission to conduct the study in their respective hospitals as well as to all the prescribers who agreed to spend their time to participate in the study.

\section{REFERENCES}

1. Hogerzeil HV, Bimo, Ross-Degnan D, Laing RO, OforiAdjei $D$, Santoso $B$, et al. Field tests for rational drug use in twelve developing countries. Lancet 1993; 4: 1408-1410.

2. Kamuhabwa $A R$, Silumbe $R$. Knowledge among drug dispensers and antimalarial drug prescribing practices in public health facilities in Dar es Salaam. Drug Healthc Patient Saf 2013; 5: 181-189.

3. Schumock GT, Walton SM, Park HY, Nutescu EA, Blackburn JC, Finley JM, Lewis RK. Factors that influence prescribing decisions. Ann Pharmacother 2004; 38: 557-5562.

4. Watkins C, Harvey I, Carthy $P$, Moore L, Robinson E, Brawn R. Attitudes and behaviour of general practitioners and their prescribing costs: a national cross sectional survey. Qual Safety Health Care 2003; 12: 29-34. 
5. Posser $H$, Almond $S$, Walley $T$. Influences on GPS decision to prescribe new drugs: the importance of who says what. Fam Pract 2003; 20: 61-68.

6. Vancelik S, Beyhun NE, Acemoglu H, Calikoglu O. Impact of pharmaceutical promotion on prescribing decisions of general practitioners in Eastern Turkey. BMC Public Health 2007; 7: 122.

7. Oshikoya KA, Oreagba I, Adeyemi O. Sources of drug information and their influence on the prescribing behaviour of doctors in a teaching hospital in Ibadan, Nigeria. Pan Afr Med J 2011; 9:13.

8. Massele AY, Mwaluko GM. A study of prescribing patterns at different health care facilities in Dar es Salaam, Tanzania. East Afr Med J 1994; 71: $314-$ 316.

9. Massele AY, Nsimba SE, Rimoy G. Prescribing habits in church-owned primary health care facilities in Dar es Salaam and other Tanzanian coast regions. East Afr Med J 2001; 78:510-514.

10. Javaras K. Statistical analysis of Likert data on attitudes. Thesis for Doctor of Philosophy, Balliol College University of Oxford. 2004.

11. Reddy EA, Shaw AV, Crump JA. Community-acquired bloodstream infections in Africa: a systematic review and meta-analysis. Lancet Infect Dis 2010; 10: 417432.

12. Silumbe R, Kamuhabwa A. Pharmaceutical management and prescribing pattern of antimalaria drugs in Dar es
Salaam. Masters Thesis, Muhimbili University of Health and Allied Sciences, Dar es Salaam, 2011.

13. Goldman DP, Joyce GF, Zheng Y. Prescription drug cost sharing: associations with medication and medical utilization and spending and health. JAMA 2007; 298: 61-69.

14. McGettigan P, Golden J, Fryer J, Chan R, Feely J. Prescribers prefer people: The sources of information used by doctors for prescribing suggest that the medium is more important than the message. $\mathrm{Br} \mathrm{J}$ Clin Pharmacol 2001; 51: 184-189.

15. Arroll B, Goodyear-Smith F, Patrick D, Kerse N, Harrison J, Halliwell J, Pearson J, Lay-Yee R, von Randow M. 2005. Prescribing information resources: Use and preference by general practitioners: An exploratory survey of general practitioners: Report to the Ministry of Health, University of Auckland, 2005.

16. WHO. Report of the conference of experts. The rational use of drugs, 25-29 November 1985, World Health Organization, Geneva 1987.

17. Massele AY, Ofori-Adjei D, Laing RO. A study of prescribing patterns with special reference to drug use indicators in Dar es Salaam region, Tanzania. Trop Doc 1993; 23: 104-107.

18. Losse K, Schneider E, Spennemann C. The viability of local pharmaceutical production in Tanzania. Technische Zusammenarbeit (GTZ) GmbH. 2007. Available at: http://apps.who.int/medicinedocs/docu ments/s17980en/s17980en.pdf. 